\title{
Proactively seeking new knowledge in social encounters for teaching
}

\author{
Thomas Ngo-Ye, Alabama State University, tngoye@alasu.edu \\ Jae Choi, Pittsburg State University,jchoi@pittstate.edu \\ Dexter Gittens, Alabama State University,dgittens@alasu.edu
}

\begin{abstract}
The Information Systems (IS) faculty has the duty of preparing future IS professionals with relevant skills. Thus, IS faculty need to stay updated with the new technology and trends in the Information Technology (IT) industry. To achieve this goal, we advance the approach of proactively seeking new knowledge in all social encounters. By exploiting the opportunities of these social interactions, IS faculty can obtain new knowledge and valuable insight for teaching. In this research, we demonstrated this approach with our practice. We also reported the discoveries of our preliminary case studies. This study makes the following potential contributions. First, this research showcases how to broaden IS faculty's knowledge horizon to keep up to date by actively exploiting social encounters. Second, the cases reported here can be adapted and used as teaching materials for classroom discussion in appropriate IS courses. Third, IS students will benefit from the industry insights, emerging technology trends, and career advice derived from these cases.
\end{abstract}

Keywords: proactively seeking new knowledge, social encounters, teaching, information systems

\section{Introduction}

Information Systems (IS) is a dynamic field with constantly emerging innovations and new trends. As a result, there is a high demand for well-trained IS professionals. With the expectation of filling the pipeline for IS professionals, what can IS faculty do becomes a salient question for the IS discipline (Kuechler, McLeod, \& Simkin, 2009). IS faculty need to keep up with the latest developments of the IT industry and teach students relevant content. Faculty can invite college IT staff to give IS students a campus network tour, discuss network administration in a telecommunication class, and facilitate faculty self-learning (NgoYe \& Baxter, 2015). Faculty can also perform social learning by engaging in social encounters with adult students, alumni, college IT staff, local college faculty, and local business and IT professionals (Ngo-Ye, McNeal, \& Gittens, 2017). How can IS faculty be updated with new technology and trends? First, we can always adopt the latest version of IS textbook from premier publishers. Second, we need to participate in as many formal professional development and training activities as possible. Third, we can acquire new knowledge at no cost by Googling and watching YouTube videos. However, in addition to the above three methods, we suggest that IS faculty proactively seek knowledge by exploiting all formal and informal social encounters.

In this study, we report our practice of pursuing new knowledge via all forms of social encounters. In addition, we gave a detailed description of each encounter and what new insights we discovered using a case format. This research can make important contributions in several aspects. First, it showcases a method of how to broaden IS faculty's knowledge horizon to keep up to date. Second, the cases presented here can be used as teaching materials for classroom discussion in suitable IS courses. Third, IS students can benefit from the industry insights, emerging technology trends, and career advice derived from the cases. 


\section{Methodology}

To proactively seek new knowledge relevant to IT and business, we must always be mentally alert in all kinds of social encounters. We always consciously remind ourselves what new things we can learn from social interactions. Social encounters include academic conferences, industry workshops, informal conversations with faculty and local businesses, and IT club meetings with business owners and IT professionals. Additionally, social encounters may include having industry guest speakers' and college IT managers talk to students, having students' class field trips, having informal conversations with alumni, and engaging in companies' information sessions, among others. During these social encounters, we actively absorb as much information as possible. If possible, we write down notes during these encounters. After a social encounter, we transcribe what we have learned into a digital text document as soon as possible, as our memory is still fresh. During a social encounter, we also purposely guide the discussion topic toward our interest by asking the relevant questions. The following cases are based on the digital text documents we recorded. The case study method is an invaluable tool in IS research (Darke, Shanks, \& Broadbent, 1998; Lee, 1989). Therefore, we adopted the qualitative case study approach for this research. The cases presented in this study are to the extent of our best effort and knowledge.

\section{Results}

In this section, we report the social encounters we engaged in and the knowledge and insights we learned. Table 1. summarizes the social interaction scenarios for the 17 cases, including the date of social interaction, the social setting, and the actors involved.

Table 1: Social Interaction Scenarios for the 17 Cases

\begin{tabular}{|l|l|l|l|}
\hline Case \# & $\begin{array}{l}\text { Date of } \\
\text { Social } \\
\text { Interaction }\end{array}$ & Social Interaction Scenario & Actors Involved \\
\hline 01 & $03 / 22 / 2014$ & $\begin{array}{l}\text { A casual conversation during a regional } \\
\text { academic IS conference in the U.S.A. }\end{array}$ & $\begin{array}{l}\text { An IS professor met at the } \\
\text { conference }\end{array}$ \\
\hline 02 & $06 / 2014$ & $\begin{array}{l}\text { A meeting with local business owners as part } \\
\text { of the process of applying for an International } \\
\text { grant }\end{array}$ & A small local business owner \\
\hline 03 & $01 / 28 / 2015$ & $\begin{array}{l}\text { An informal conversation with a faculty } \\
\text { colleague at our school }\end{array}$ & A faculty colleague \\
\hline 04 & $03 / 26 / 2015$ & $\begin{array}{l}\text { Two IT professionals from a local Fortune } \\
\text { 500 manufacturing company came to our } \\
\text { school as guest speakers and talked to our IS } \\
\text { students. }\end{array}$ & Two IT professionals \\
\hline 05 & $04 / 2015$ & $\begin{array}{l}\text { Our college IT manager came to our Database } \\
\text { class as a guest speaker and talked to our IS } \\
\text { students. }\end{array}$ & Our college IT manager \\
\hline
\end{tabular}




\section{Issues in Information Systems}

Volume 22, Issue 2, pp. 260-275, 2021

\begin{tabular}{|c|c|c|c|}
\hline Case \# & $\begin{array}{l}\text { Date of } \\
\text { Social } \\
\text { Interaction }\end{array}$ & Social Interaction Scenario & Actors Involved \\
\hline 06 & $10 / 13 / 2015$ & $\begin{array}{l}\text { An informal meeting with an IT faculty from } \\
\text { a local higher education institution at his } \\
\text { office }\end{array}$ & An IT faculty from a local college \\
\hline 07 & $10 / 2016$ & $\begin{array}{l}\text { Meetings and presentations from an academic } \\
\text { conference and an industry technology } \\
\text { conference }\end{array}$ & $\begin{array}{l}\text { Professors and IT professionals } \\
\text { attended the academic conference } \\
\text { and the industry technology } \\
\text { conference }\end{array}$ \\
\hline 08 & $03 / 14 / 2016$ & $\begin{array}{l}\text { Meetings with a business owner and a } \\
\text { manager from a government agency during a } \\
\text { school field trip to visit a large metropolitan } \\
\text { area }\end{array}$ & $\begin{array}{l}\text { A business owner and a manager } \\
\text { from a government agency }\end{array}$ \\
\hline 09 & $03 / 29 / 2016$ & $\begin{array}{l}\text { We brought several of our IS students to } \\
\text { attend a networking event sponsored by a } \\
\text { local business and IT club. We interacted } \\
\text { with IT professionals and business owners. }\end{array}$ & $\begin{array}{l}\text { An IT job agency recruiter, an IT } \\
\text { professional, and an IT contractor }\end{array}$ \\
\hline 10 & $08 / 2016$ & $\begin{array}{l}\text { An introductive workshop sponsored by a } \\
\text { local Project Management association hosted } \\
\text { at our school }\end{array}$ & A Project Management professional \\
\hline 11 & $11 / 10 / 2016$ & $\begin{array}{l}\text { A renowned local business owner/IT } \\
\text { professional came to our school as a guest } \\
\text { speaker and spoke to our IS students. }\end{array}$ & $\begin{array}{l}\text { A renowned local business owner/an } \\
\text { IT professional }\end{array}$ \\
\hline 12 & $04 / 18 / 2017$ & $\begin{array}{l}\text { A local IT professional came to our school as } \\
\text { a guest speaker and spoke to our IS student } \\
\text { club. }\end{array}$ & $\begin{array}{l}\text { A local IT professional/a Microsoft } \\
\text {.NET developer }\end{array}$ \\
\hline 13 & $\begin{array}{l}05 / 05 / 2017 \\
\text { and } \\
08 / 09 / 2017\end{array}$ & $\begin{array}{l}\text { We had an informal conversation with a } \\
\text { recent graduate who was a non-traditional } \\
\text { adult returning IS student. }\end{array}$ & $\begin{array}{l}\text { A non-traditional adult returning IS } \\
\text { student }\end{array}$ \\
\hline 14 & $07 / 07 / 2017$ & $\begin{array}{l}\text { We had an informal conversation with a } \\
\text { recent graduate, a Computer Science major, } \\
\text { of our university. }\end{array}$ & $\begin{array}{l}\text { A recent graduate/a Computer } \\
\text { Science major }\end{array}$ \\
\hline 15 & $10 / 19 / 2017$ & $\begin{array}{l}\text { A local cybersecurity professional came to } \\
\text { our school as a guest speaker and talked to } \\
\text { our IS students. }\end{array}$ & A local cybersecurity professional \\
\hline 16 & $10 / 11 / 2018$ & $\begin{array}{l}\text { A large IT and business consulting services } \\
\text { firm came to our school and held an } \\
\text { information session for IS students. }\end{array}$ & $\begin{array}{l}\text { A hiring manager from a large IT } \\
\text { and business consulting services } \\
\text { firm }\end{array}$ \\
\hline 17 & $12 / 2019$ & $\begin{array}{l}\text { We encountered an IT professional at a local } \\
\text { technology meetup event and had an informal } \\
\text { conversation. }\end{array}$ & A local IT professional/a DBA \\
\hline
\end{tabular}

\section{Case 1}

While attending an academic conference, we had an informal conversation with an Information Systems (IS) professor. We will refer to this IS professor as Dr. Anthony (a pseudonym for convenient communication). Dr. Anthony believes in the technical side of IS. He encourages his son to study computer science and go to Silicon Valley to pursue opportunities rather than work in a large company for a conventional and stable job. We learned that for bright young talent with strong technical skills, Silicon Valley remains a top attraction. 


\section{Issues in Information Systems}

Volume 22, Issue 2, pp. 260-275, 2021

\section{Case 2}

During the process of applying for an International grant, we interviewed a small local business owner. We will refer to this business owner as Mr. Brent (a pseudonym for convenient communication). Here is what we learned from our discussion with Mr. Brent. First, Mr. Brent told us that he always asked if the job applicant had a goal for two, three, or four years from the present when hiring a new graduate. This question is a "killer criterion," according to Mr. Brent. If a job candidate had no goals, the person was not a good candidate, said Mr. Brent. Therefore, we learned that it is critical to remind our students to set up an intermediate career goal.

\section{Case 3}

During our informal conversation with a faculty colleague at our school, we learned that he attended a technology conference. He informed us that he met with some industry practitioners before the conference and he asked them what qualifications were needed for working in the Big Data field? For example, does it require any programming skill or knowledge any programming language? They said that since it is so difficult to find people with those programming skills, they will hire intelligent young people and then do on-the-job training. Thus, we realized the importance of the quality of being trainable for students.

\section{Case 4}

We invited two IT professionals from a local Fortune 500 manufacturing company to talk to our IS students. We will refer to them as Ms. Alice and Mr. John (pseudonyms for convenient communication). Here is what we learned from their talk.

Ms. Alice and Mr. John are performing Java-based application development work in their company. They spoke about their work, the job interview process at their company, what kind of skills are required for working in the IT field, and how to prepare to be successful in a professional IT career.

Ms. Alice started as a Computer Science major and then switched to a math major. She graduated with a math degree. Under the supervision of a system engineer, Ms. Alice is now a system developer. Her daily work deals with databases. For example, she needs to read COBOL codes, turn them into SQL, and write stored procedures. Ms. Alice has a passion for technology. At the same time, she has a long-term plan of moving up into management. Ms. Alice had worked nine months in the group so far. Ms. Alice has developed a solid professional identity. She said that she tries to stay on top of things in the IT field and stay relevant. Ms. Alice believes that it is essential to learn new things, such as the Spring framework. She advises students to always Google things that they do not know at work in the future. Sometimes Google gives results that are not precisely what a person needs, but people can change code to match what is needed.

Ms. Alice asked students what was the purpose of the job of a programmer? Most people may think it is about writing code. Writing code is what a programmer does. However, the purpose of a programmer in a firm is to make a product that does what the business end-user needs/wants. In other words, the purpose is to develop applications to satisfy users. Ms. Alice's job is to give end-users - customer representatives of her firm - the best user experiences when the users use the customer service web interface. Programmers need to learn new kinds of information and explain and sell the users the idea of using new technology by demonstrating the benefits. Programmers need to understand what is going on, such as business rules, what they are doing for the business, not just coding. 


\section{Issues in Information Systems}

Volume 22, Issue 2, pp. 260-275, 2021

It is vital to have the ability to solve a problem as a programmer. Ms. Alice's Computer Science schooling and Math degree trained her to develop problem-solving skills. Ms. Alice studied Java in her Computer Science classes. She took Java I and Java II courses while in college. However, Ms. Alice did not know SQL when she got the job at the firm. She learned SQL on her job.

Students asked Ms. Alice what level of math was used in her programming job? Ms. Alice said that algebra is essential and sufficient for all their programming work. On the other hand, Calculus is not used in programming work. However, Calculus is helpful in the long run to improve a person's thinking. Programmers do not need to worry about not knowing the advanced math model or logic, such as inventory turn or replenish reorder point. Business functional experts will explain in detail those kinds of models. Programmers can then implement the business logic into the code. No one expects a programmer to come up with such an advanced model on his/her own.

However, a programmer needs to learn all the technical parts of Java. There are many resources on the Internet, such as videos and step-by-step tutorials. It is easy to search on the Internet at work and figure out a problem rather than asking coworkers. However, after spending a lot of time on the Internet, if a person still did not solve the problem, then one needs to ask a coworker. Additionally, if one does not understand the explanations on Internet, then one will not understand explanations by coworkers either.

Seventy percent of Ms. Alice's work is primarily concerned with maintenance. The other $30 \%$ of work is writing new code. Many new entry-level programmers do routine maintenance work in the beginning. Ms. Alice was fortunate to have the opportunity to do system migration work. The company moved from an old system (IBM Websphere) to a new system (JBOSS Server). IBM Websphere is old technology, and does not have the technical support when the contract expires; leading to millions of dollars in costs to get the technology support after the expiration of the contract. The new JBOSS system is much cheaper. The migration decision to convert to new technology is all about money. Also, the migration is from the old Java framework (Struct) to the new framework (Spring). Programmers need to understand both frameworks for the move. They do not use all the features of the Spring framework. They only use some pieces of the Spring framework, as the framework encapsulates many things.

Ms. Alice learned PHP, and web programming from online tutorials. Once you learn Java, it becomes uncomplicated to learn PHP because one already understands programming concepts. It takes only a few weeks to learn the PHP syntax. Ms. Alice's parent has a business selling smartphones online. So Ms. Alice built the website for her parent's business with PHP and MySQL because both PHP and MySQL are free. Ms. Alice emphasized that one can learn things if one has the time and "want" or the desire to learn. A person needs to "want," therefore, "passion" is essential!

Ms. Alice's company uses Eclipse for Java, C++, and PHP. They will soon be coding COBOL in Eclipse. Eclipse is the most advanced IDE. In their group, Ms. Alice uses the following technologies: HTML Javascript for fancy and cool stuff on the web to be interactive like popup, JQuery - built on Javascript, Java, SQL - IBM DB2, and Stored procedures. CISC is old COBOL-based technology. Traditionally, Ms. Alice's firm uses CICS to call the COBOL program. However, they switched to JBOSS and moved to stored procedures, and are not using CICS anymore. Ms. Alice's company has double Security in place. Also, Ms. Alice's company has a dedicated group of people in charge of Security. Java and Microsoft .NET are two dominant and competing programming languages in the industry. Ms. Alice's company mainly uses Java for web applications. Other groups in the company use Microsoft .NET and even Power Builder.

John said that his firm lacks good Database Administrators (DBAs). It is a very technical job, with room for growth, and needs a good understanding of many things. Ms. Alice said that with Big Data becoming 


\section{Issues in Information Systems}

Volume 22, Issue 2, pp. 260-275, 2021

popular, DBA is definitely in demand. SQL is essential for the success of businesses, and for the development of adequate programming skills. SQL helps with proper data management. In their group, there are business analysts. Business analysts focus more on the business side, understanding what business wants, and not the technical side, although they need to understand technology. Business analysts write specifications, develop an overall picture of the organization, make flow charts, and express basic ideas and documentation. At Ms. Alice's company, the original specification documents were not updated. During the meetings, programmers are responsible for writing down the notes of required changes. Documentation is very time-consuming, costs resources and if not done efficiently the programmers will get all the blame. Ms. Alice's company has time pressure - want to get things done fast. Therefore, documentation is often sacrificed either due to not documenting or under-documenting. It is important to have the expertise in such areas as documentation, UML, and flow charts. In other companies, it may be different.

At Ms. Alice's company, applications go through a sequence of tests, including Unit tests, business tests, regression tests with a large volume of data, usually automatic tests. As a result, important things and critical applications get more tests than less important or less critical applications.

Ms. Alice's company is moving away from COBOL. Ms. Alice's company has many COBOL applications similar to many big businesses such as Home Depot, and Railroad. There are more jobs for college students in Atlanta Georgia using COBOL. Currently, Ms. Alice's company maintains COBOL on the mainframe mainly for those very complicated COBOL functions. COBOL is still around for businesses to run operations thus It is crucial to understand COBOL. It is good to know both COBL and Java. However, Ms. Alice does not need to write COBOL code. For Ms. Alice's job, she wrote SQL and stored procedures to replace COBL functions. The industry trend is clearly to move away from COBOL, however, there is still a need to maintain COBOL applications for many years. It is too expensive to replace all existing COBOL applications by rewriting them in a new language such as Java. It is difficult for Ms. Alice's company to find enough work to keep their COBOL programmers busy right now. COBOL programmers' salary is higher than that of Java programmer leading to a high risk that COBOL programmers may be laid off in the future. When a company has a new opening COBOL position, it is very likely to be filled internally. When hiring COBOL programmers from outside, companies prefer COBOL programmers with much work experience rather than college graduates who learned COBOL in a class. John recommends that young college students do not bet their careers on COBOL. Students should take as many programming courses offered as possible. COBOL courses should not be required in the MIS curriculum anymore. COBOL should be offered as an optional elective course as recommended by both John and Ms. Alice.

According to John and Ms. Alice, their work mainly uses Java and SQL for web applications. They recommended having a web application development course using Java and SQL technology. Students should learn how to develop a Java-based web application to interface with a back-end database in the course. SQL and stored procedures are used to retrieve data from the Database and write updated data. The user interface is webpage enhanced with Javascript and AJAX. The Java Web Application course would require that students take Java I and Database Management courses as prerequisites. In Java I, students learn the basic concepts of programming, object-oriented design, and implementation.

\section{Case 5}

We invited a college IT manager to talk to our IS students in our Database class. We will refer to the college IT manager as Mr. Bruce (a pseudonym for convenient communication). We reported what we learned from Mr. Bruce's talk below. 


\section{Issues in Information Systems}

Volume 22, Issue 2, pp. 260-275, 2021

Before becoming a college IT manager, Mr. Bruce had extensive experience as a database administrator. Mr. Bruce asked students where does a DBA have the clear segregation of job responsibility? His answer was in large organizations. A DBA can focus on the DBA's role at large organizations because he/she needs to manage many databases - maybe a farm of database servers, maybe across the country, or maybe many regional office databases. Due to the scale of DBA work, a DBA in a large organization can concentrate and specialize in the role. However, most DBAs in small and medium-size companies spent much time doing many other things (writing reports and data analysis), not limited to the traditional role. Thus, the line is blurred between DBA and system administrator.

Mr. Bruce explained that databases are never alone. Databases must have some applications on top of it. End-users use the database applications. After a database is set up and tuned at our university, most of the DBA time is spent on the Student Information System (maintain and develop forms and reports), which manages and stores student academic and financial payment information. Mr. Bruce asked students, in general where does a DBA spend most of the time after setting up a database and tuning a database? His answer was retrieving data from databases to support the operation and decision-making of the organization. Additional roles of DBA include report writing, data analysis, and server administration, added Mr. Bruce.

\section{Case 6}

We had an informal meeting with a faculty in a local higher education institution. We refer to the faculty as Dr. Alex (a pseudonym for convenient communication). Here is what we learned from Dr. Alex.

Dr. Alex has the expertise and extensive experience in teaching Network and Telecommunications. Dr. Alex suggested we contact state government agencies that donate old routers and switches when they update their equipment. Then, we can use that donated equipment for classroom teaching.

Dr. Alex believes that in higher education, the most important two things are reading and writing skills. These skills can even predict hands-on skills. Without good reading skills, students cannot develop good comprehensive skills. Dr. Alex said that to succeed in job placement, a student needs three things: education, skill and experience, and certificate.

Dr. Alex used to work in the U.S. military and was trained to be disciplined and following orders. He used to work at a large regional university for computer helpdesk support. Dr. Alex rode a bicycle to different buildings to support. When he moved to our city, he had a job interview at a large regional bank. The hiring manager asked him to take off his suit and tie and follow him to the computer room and network closet. Then he was given a piece of paper with ten questions to solve. They were all real problems faced by the IT helpdesk in the bank. The interview questions included a few issues were recently encountered by the IT helpdesk of the bank. Dr. Alex said that he did not like interview questions such as the job candidates' goals in five years. He wants to interview someone to discover whether he/she has real technical skills to solve a technical problem. Dr. Alex's job interview experience at the large regional bank shaped his views and influenced his teaching.

We learn from Dr. Alex the opportunity of obtaining equipment donated by state agencies, the importance of reading and writing skills, and the significance of possessing hardcore technical skills to solve real problems for job placement.

\section{Case 7}

We participated in an academic conference and an industry technology conference. We learned several new trends from these two conferences. 


\section{Issues in Information Systems}

Volume 22, Issue 2, pp. 260-275, 2021

We learned that one of our State's primary electricity power companies and a large health insurance company still used COBOL for its business operation because it is hard to integrate legacy systems. Database as-a-service or DBaaS became famous as a variant of cloud computing service. SAP offers the Business Objects Cloud on its HANA Cloud Platform. In addition, there are some SAP Certified Apps. The certification includes the name of the APP producer, and reviews convey the trust of the application. Some are certified by SAP. We heard that https://open.sap.com/ has free educational materials - open online courses by SAP with complementary microlearning and podcasts!

We heard of a new award token system called a digital badge. A digital badge shows an individual has a credential after completing a course or passing a test. There are many kinds or levels of digital badges, such as class badges. There are free badge designer tools to design and give out digital badges, such as Accredible's badge creator (https://www.accredible.com/badge-designer/), creating a professional digital badge free. Students can earn digital badges through classwork and passing some certification tests. Then, students can proudly display the digital badges in the resume or online portfolio to enhance their job application prospects. We learned that https://edtechbadges.wordpress.com/ provides tutorials to assist students in setting up their e-portfolio, collecting their earned badges, and adding digital badges to the eportfolio on WordPress.

\section{Case 8}

We led a group of business students on a school field trip to visit a large metropolitan area of our region. We met a business owner and a manager from a government agency and learned a lot from the encounter.

Mr. Alan (a pseudonym for convenient communication) is a business owner and a technology entrepreneur. He runs a technology entrepreneur center. Mr. Alan said that the most important thing to differentiate is the unique execution of a business plan. Technology such as writing a mobile app is secondary or less to worry about. It is the business side that is more critical. Technology can be complex and make people think more complicated than necessary. Previously, a T1 line for network connection costs $\$ 3,000$ a month, and now it is just $\$ 40$ per month. Nowadays, it is easier for entrepreneurs to run a business because technology infrastructure is cheaper to access with the advancement of cloud computing.

Mr. Alan said that the secret for a business to succeed is to figure out something that customers must have. Mr. Alan's business provided a smartphone app, which helped influencers on a social network such as Instagram. His business model is related to brand name and marketing. Influencers must have Mr. Alan's app to do their job and make money.

Ms. Anna (a pseudonym for convenient communication) was a government manager whom we met during the field trip. We learned from Ms. Anna's that her job duties included reviewing proposals from small businesses applying to conduct government projects, and awarding contracts. Ms. Anna said that currently, cloud computing is already everywhere. It is not new and exciting anymore. Therefore, a proposal emphasizing cloud computing no longer attracts a tremendous amount of attention as before. Ms. Anna said http://www.salesforce.com has a certificate, which is very useful. Many small businesses and even government employees use http://www.salesforce.com every day, explained Ms. Anna. Therefore, a job candidate with a salesforce certificate looks unique and better, according to Ms. Anna.

Ms. Anna stated that government agencies required many certifications, such as Project Management Professional (PMP) certification. Many IT jobs were outsourced in recent years, but some IT support jobs exist in the Federal government. Ms. Anna said that a new college graduate could work in a government 


\section{Issues in Information Systems}

Volume 22, Issue 2, pp. 260-275, 2021

program in the first two years at a paid internship job with the federal government, at a starting salary of $\$ 40,000$. The exact salary depends on the positions. In the first two years, the government IT intern goes through much training and must take a few certification exams. An internship is the best way to get through the door of the federal government, according to Ms. Anna. The federal government has job series. To work for government agencies, job candidates need to go through a thorough background check and security clearance that takes time. Ms. Anna urged students who were interested in a government internship program to apply early. In the first two years of the program, there are automatic promotions and salary raises. After the two-year internship period, one can become a regular employee of the government. The first three years are the probation period. After these three years, the job is secure in the government. In the government work system, there are factors of time and grade for promotion and salary raise. After serving specific years in the government, one is eligible to apply for promotion. One can also transfer within different federal agencies. A government employee may also relocate to different states and cities if there is an opening. Students can check https://www.usajobs.gov/ and choose "students and recent graduates." Some positions on this website are only open for a few weeks. Therefore, Ms. Anna suggested that students should apply early.

\section{Case 9}

We led several of our IS students to a networking event sponsored by a local business and IT club to help students with networking and finding jobs. We encountered several IT professionals, business owners, and IT job agency recruiters. We learned the following interesting things.

A recruiter, Ms. Catherine (a pseudonym for convenient communication), told us that she currently had a junior IT position open for new graduates. Ms. Catherine said she could come to our university, talk to IS students, and review and improve resumes. She could also refer ours IS students for summer internships. Our State will have a budget and be ready for December graduates to tell them what positions are available in October but it is too early at this time. One-hundred and twenty IT contractors were working for Ms. Catherine's company in downtown Montgomery. Our State does not have money for permanent IT employees but has money to hire IT contractors. A contract is usually renewed every year. There is always IT work to do for contractors. Ms. Catherine just filled seven positions requiring A+ certification. Ms. Catherine had another client do a project to convert IBM Lotus Notes to Microsoft SharePoint.

Ms. Catherine said that the IT job market was OK in the past few years. However, when one of our students asked Ms. Catherine which strategy was better (knowing one technology in depth versus knowing a bit about everything), she responded that knowing a little about everything is more suitable for most positions. Ms. Catherine told us that as a recruiter, the annual base salary is $\$ 30,000-\$ 40,000$. However, commissions are unlimited. There are incentives to locate suitable candidates to match clients. One recruiter earned a total of $\$ 72,000$ in his/her first year. It is a plus for a recruiter to have an IS education background. Therefore, Ms. Catherine found two developers with IS backgrounds as recruiters to help her.

Ms. Catherine suggested that we consider exploring the CAPS program. Here is how the CAPS program works. First, a recruiter works with the CAPS program between state agencies. Next, IS students from our school form a team. Then, a recruiter finds a state project for the team. While State agencies pay each other, students get some pay and earn real-world work experience. In one successful case, a student got a job of $\$ 82,000$ straight out of college because of CAPS experience.

One IT professional told us that a major state university has cooperative programs where students intertwined course work and internships. As a result, the IT professional completed his bachelor's degree in five years without any personal break. The IT professional recommended we implement such co- 


\section{Issues in Information Systems}

Volume 22, Issue 2, pp. 260-275, 2021

operative programs at our university to strengthen our students' work experience for better job placement in the future.

An IT contractor told us that contractors work hourly and usually get a higher hourly rate. Nevertheless, contractor jobs come with no benefits and vacations. In addition, a contractor had to buy his/her individual health insurance. Therefore, the IT contractor preferred long term contract like 18 months, due to relocation costs. The IT contractor mentioned that he was working on a project for the state Medicare. The Project was about web programming integrating Microsoft Dynamic CRM. The desired skills for this Project included programming skills plus writing code to interfere and integrate CRM, especially Microsoft Dynamic.

\section{Case 10}

We participated in an introductory workshop sponsored by a local Project Management association. As a result, one Project Management professional shared his industry insight with us. We refer to the Project Management professional as Mr. Billy (a pseudonym for convenient communication). Here is what we learned from the interaction with Mr. Billy.

During the training, Mr. Billy mentioned that sometimes organizations have an employee who is not a team player. One faculty member asked why the organization did not let go of that employee, a non-team player. In our teaching, we always emphasize and promote the ideas of good teamwork and collaboration. Therefore, we were puzzled by the phenomenon that organizations sometimes tolerated and kept a nonteam player. Mr. Billy explained the complexity of real-world situations in organizations. If a non-team player does not possess any specialty, in other words, easily replaceable, it is an easy decision to let him/her go. However, sometimes the scenario is more complicated. When a non-team player possesses specific expertise that no other employees has, then management needs to tolerate his/her anti-norm behavior and work with him/her, said Mr. Billy. Thus, there is a delicate balance the company must face When the benefit a non-team player brings to the organization outweighs the pain and damage he/she causes, the organization has to put up with it. Conversely, when the efforts to cultivate desired behavior are too much, or the damage and pain are unbearable relative to the benefit that a non-team player brings, the organization has to make a tough choice to let him/her go, stated Mr. Billy. Therefore, we learned to appreciate the complexity of real-world organizations and be mindful of the delicate tradeoffs.

\section{Case 11}

We invited a renowned local business owner to come to our school and talked to our IS students. We refer to the renowned local business owner as Mr. Brandon (a pseudonym for convenient communication). Here is what we learned from Mr. Brandon's talk.

Mr. Brandon was also a technology leader and IT professional, alone with being a successful businessman. He recently spent a years' worth of effort bringing together local technology talents and entrepreneurs. He spearheaded a local technology club. In the beginning, the club focused on creating awareness, then it worked on startup and business development. The club offered workshops for serious entrepreneurs. Mr. Brandon told students that learning the craft was most important. A degree and certifications can help a student to get through the door of an employer. Nevertheless, in the end, it is one's ability to do the work and solve problems that determine whether a person can keep his/her job and not the person's GPA or degree. Mr. Brandon suggested students adopt the mindset of a technology startup - not asking permission. In many organizations, IT is critical to run businesses and make decisions. 


\section{Issues in Information Systems}

Volume 22, Issue 2, pp. 260-275, 2021

According to Mr. Brandon, IT is very different from other disciplines. Students can now buy cheap IT equipment, such as routers and PCs, and experiment with them. Much software behind enterprise systems used by Google and Facebook are free and open-source, therefore, students can download and study them. Real-world systems are the same as what students can get their hands on. The only differences are that the scale, and new versus old version. Government agencies retire old computer systems every year, and students may buy those at a low prices. Alternatively, students can buy cheap computers from eBay. Instead of being Facebook consumers, students should be creators of technology, which powers large firms, such as Facebook and Google.

Mr. Brandon encouraged students to create their small computer labs in dorms or apartments. Then, students should do some projects there and create something. Mr. Brandon said it was better to showcase those projects during job interviews than telling the interviewer you worked as an intern at a computer lab, where you cannot experiment with your employers software. For IT professionals, the most crucial thing was to experiment and explore things, proclaimed Mr. Brandon. Mr. Brandon assured students not to worry about the lack of experience. By doing one's lab, one can have rich experience.

Mr. Brandon summarized three critical things about Security. First, students need to master the basic security concepts learned in Security class and textbooks. Second, advanced Security Cryptology requires advanced mathematics. Therefore, students need solid math skills. The third and most important one is that of the mindset. It is the most challenging part. Students should think like Security criminals. Security criminals poke around systems to break in. Female students are more likely to fit in this way of thinking or defend computer systems.

Mr. Brandon believed that Silicon Valley has the best debt-for-equity model for technology innovation. Therefore, if one aims to do technology innovation, one should move to Silicon Valley. There are many dreamers, and like-minded innovators who can inspire each other. Mr. Brandon did not recommend putting one's own money into starting a small business because it is too risky. Many small businesses will eventually fail. Instead, one should try to use revenues from customers to fund the small business. Finding the right and sound business partner is critical. Wrong business partners have ruined many lives. Once legally partnership is formed, it is tough to separate.

\section{Case 12}

We invited an IT professional as a guest speaker to have a discussion with our IS student club. We refer to the guest speaker as Mr. Blake (a pseudonym for convenient communication). Here is what we learned from Mr. Blake's talk.

Mr. Blake has been Microsoft .NET developer for many years, and used to work at Microsoft. Mr. Blake said that currently, there was a trend of databases moving into the cloud. Another emerging trend was the increasing adoption of the Agile kanban methodology, according to Mr. Blake. Kanban is a popular framework that is used to implement agile and DevOps software development. In addition, Kanban requires real-time communication of capacity and full transparency (https://www.atlassian.com/agile/kanban).

Mr. Blake mentioned to students that he used a to-do list chart with priority and ticket numbers to keep track of his work. At his work, they are pushing computer program code changes or commits to a remote repository, according to Mr. Blake. In other words, they upload local repository content (code changes) to a remote repository, such as GitHub storage (https://github.com/). Mr. Blake also discussed the significance of the process maturity model for continuous improvement with feedback and measures. 


\section{Issues in Information Systems}

Volume 22, Issue 2, pp. 260-275, 2021

Mr. Blake stated that formal education, such as a college degree, is critical for lifelong happiness. He recommended that students finish school first. Work very hard to get a college degree first, said Mr. Blake. One needs to have a job lined up before graduation. The first job is unlikely one's ideal job, proclaimed Mr. Blake. Mr. Blake shared the following life lessons with students. First, he cautioned students that it was better to fail early and often than late. Second, it was good to work in an area that one likes in the first place. Third, after a person had a job find a different hobby. Fourth, be passionate, be oneself, be genuine, be cocky, and it is OK.

\section{Case 13}

We had an informal conversation with a recent graduate who was a non-traditional adult returning IS student. We refer to the student as Mr. Arthur (a pseudonym for convenient communication). We reported what we learned from Mr. Arthur below.

Mr. Arthur told us that one could buy good network equipment such as a router on eBay for a meager price. The reason being that some owners did not have the experience and thought something was wrong with their network equipment. In one case, a buyer heard a slight noise inside the router box but after opening the box, the buyer saw that the flash memory was dislodged from the memory slot. Maybe the box was shaken, and memory was out. However, after pushing the memory back into the slot firmly, the router works fine.

In a second case, the router was formatted, and the firewall was also formatted, said Mr. Arthur. When the power was on, it looked normal. Nevertheless, when power was off for maintenance, it seemed as if it broke down and did not function. Therefore, it was sold at a low price on eBay. After researching for three hours, the buyer was able to fix the problems and load everything in memory with tools such as TFTP. Now it works perfectly. Next time for the same problem, it may only take 30 minutes to fix, proclaimed Mr. Arthur.

Mr. Arthur told us that he passed both CompTIA Security+ and CompTIA Network + certification exams. Both exams were very hard, said Mr. Arthur. The Network+ exam is even more challenging than the Security + exam, according to Mr. Arthur. There is a new certification exam from CompTIA called CASP which is higher than Security + . It does not require previous professional working experience in Security to take CASP. Therefore, anyone can take CASP.

On the other hand, certification exam CISSP requires several years' previous experience in Security, with proof of work experience. CISSP and CASP are of the same level of difficulty. Security+ exam will be upgraded to a new and more complex form. The current Security+ exam with many new questions is more challenging than the previous version of the Security+ exam. Networking and Security knowledge changes very fast. For example, now SSL is no longer used in the corporate world. TLS is used instead.

Mr. Arthur was preparing to take the CompTIA CASP certification exam in the coming weeks. CompTIA CASP is a higher-level certification than Security+. According to Mr. Arthur, CASP targets the CIO-level management, managing and implementing IT from a global security perspective. CASP tests what a CIO should know. CASP also covers governance, which is not part of Security + . If one passes CompTIA CASP and continues $\mathrm{CE}$ (continuous education), it will automatically renew lower certifications from CompTIA, such as A+, Network + , and Security + . Mr. Arthur stated that the knowledge of Network + and Security + are closely related. Network + is more technical than Security + . Network + focuses on how to do things. Security+ is more conceptual, emphasizing why certain things are done. A Security+ exam has around eight simulation performance-based questions and 64 multiple-choice questions. "Testout" is a software, which 


\section{Issues in Information Systems}

Volume 22, Issue 2, pp. 260-275, 2021

has a Security+ test bank. A local Security+ Bootcamp program uses "Testout" solely for preparing students for the Security+ exam.

After returning from his summer internship, Mr. Arthur shared what he learned with us. Mr. Arthur told us that hiring managers preferred to hire someone who wants to learn new skills and grow professionally. The critical question was, does one want to be better professionally? Hiring managers did not want to hire someone who just wanted a job and repeated what he/she already knew by doing the same thing.

\section{Case 14}

We had an informal conversation with a recent graduate, a Computer Science major, from our university. We refer to the student as Mr. Albert (a pseudonym for convenient communication). We reported what we learned from Mr. Albert below.

Mr. Albert recently started working as an IT contractor in a large manufacturing firm GHI (a pseudonym for convenient communication). He worked at the IT helpdesk and answered phone calls. One common problem is that users forget their passwords. Therefore, Mr. Albert needed to reset passwords for users. Users need to fill in a request form to install the software. At firm GHI, phones are set up to go through the Internet. Voice data go through Ethernet. The phone system is already integrated into the data network. Some web applications use old technology and have to use Microsoft Internet Explorer. Mr. Albert used software to manage IP addresses. Internet access is allowed for the plant of GHI. However, certain websites are blocked. Mr. Albert stated that generally, our university had newer technology than firm GHI. In the future, he will learn how to set up a printer. Mr. Albert's daily job involved hardware troubleshooting and issues related to access to the Internet. Firm GHI used paper request forms to keep track of requests, like a ticket system. Users must describe what is wrong with the computer.

Mr. Albert had a smooth transition from a university student IT worker to an IT contractor at firm GHI because of his IT work experience at our university. He is doing similar things in both places. The IT department at firm GHI has three contractors from different companies. Their boss is an employee of firm GHI, not a contractor. At the end of every workday, Mr. Albert needs to write a brief report of what he did during the day. It is usually a five bullet-point summary of what he did. At the end of a week, Mr. Albert needs to combine his five-day reports into a weekly report. At the end of a month, Mr. Albert needs to compile his monthly report, a combination of weekly reports. The reports are emailed to the head of the department (HOD) for review via Outlook. The IT department holds a monthly meeting to discuss what they did and any new projects.

At firm GHI, they used Outlook to share files. There are many user problems. Users did not know what to do. It is not IT's job to fix it. Sometimes users got confused. Mr. Albert cannot be away from his cubical for too long, because somebody will call the helpdesk and the caller will be dissatisfied if no one answers the phone. As a student worker at our university, Mr. Albert does not have the pressure to be at his desk all the time. Also, at our university, there is no requirement for daily, weekly, and monthly reports. Sometimes, users at GHI call in for help 30 minutes before the end of the working day (4:30 pm), when the actual incident happened four hours ago. Ideally, users should call earlier to give Mr. Albert more time to work on it. Mr. Albert's working schedule is Monday through Friday, 8:00 am to 5:00 pm. If Mr. Albert needs to work overtime, he needs to get his manager (HOD) 's approval first.

The issue with firm GHI is that many things are slow, and work was not completed in a timely manner. The paperwork was prolonged. Mr. Albert got his paycheck late. After working there for a month, Mr. Albert still did not have his company badge. Two forms of identification were needed for a worker at GHI. The 


\section{Issues in Information Systems}

Volume 22, Issue 2, pp. 260-275, 2021

first one was for driving a car through a gate and the second one was for walking inside the building. A third form was needed for Mr. Albert to get access to the office. Fortunately, the security guards know Mr. Albert's face and thus let him in manually. Mr. Albert was still waiting for the result of his background check. After clearance, Mr. Albert would get his company badge.

\section{Case 15}

We invited a local cybersecurity professional to talk to our IS students. We will refer to the cybersecurity professional as Mr. Anderson (a pseudonym for convenient communication). We reported what we learned from Mr. Anderson below.

Mr. Anderson gave the following advice to young IS students. First, one needs to volunteer in college's computer labs or local government computer labs to get experience. Second, one should obtain IT certifications. For example, Security+ is good. Third, CISSP is the required certification to work in cybersecurity. Finally, CISSP is like the bar exam for lawyers and attorneys.

\section{Case 16}

A large IT and business consulting services firm came to our school to hold an information session for IS students. We refer to the firm as JKL (a pseudonym for convenient communication). We report what we learned from JKL's information session below.

We raised the question of how a student can stand out from the competition in job interviews and get a professional job? JKL's hiring manager recommended that students engage in an independent study to show that they are willing to do more beyond classwork. Hiring managers usually inquire about a job candidate's extra-curricular activities with regard to technology. To be successful, students must show experience with projects beyond the classroom. JKL's hiring manager also stressed the significance of critical thinking. Finally, JKL's hiring manager suggested that if a job applicant has not done a development job before the job interview, one should take online courses at http://www.udemy.com to refresh and improve one's programming skills.

\section{Case 17}

We encountered an IT professional at a local technology meetup event. We will refer to the IT professional as Mr. Adam (a pseudonym for convenient communication). We reported what we learned from our conversation with Mr. Adam below.

A while ago, Mr. Adam was one of eight newly hired senior DBAs at his big firm - ABC (a pseudonym for convenient communication). Many DBAs in firm $\mathrm{ABC}$ worked for a long time, some for more than 10 or 16 years. As a large firm, $\mathrm{ABC}$ has blue and green (plan A and $\mathrm{B}$ ) environments, production teams, quality control teams, and development teams. So it is easy to switch between testing and production. Mr. Adam's team's roles are production support, rolling out application update, yearly database software/OS update, and hardware upgrade every three years. A separate team of DBAs works on the development and design, and integration work, according to Mr. Adam. In the firm ABC, IT staffs are specialized. Firm ABC now has more than 560 databases. Each DBA handles about 20 databases. DBAs need to write scripts to automate the work, said Mr. Adam. Many DBAs do similar work, so it is OK for one DBA to take a vacation, and other DBAs can complete the work. Firm ABC does not force production support DBAs to learn new technology as long as DBAs can solve problems. However, the IT professional volunteers for some of those projects. Firm ABC only hires senior DBAs, not junior ones. There are many hierarchy levels 


\section{Issues in Information Systems}

Volume 22, Issue 2, pp. 260-275, 2021

in firm ABC. One possible career ladder path is from an architect, senior architect, director, senior director, $\mathrm{VP}$, to senior VP.

Mr. Adam told us that he recently switched to another large company DEF (a pseudonym for convenient communication), for better work-life balance. At firm ABC, Mr. Adam had to be on call sometimes. Now at company DEF, Mr. Adam is rarely called for work in the after-hours and on weekends. Most of company DEF's existing clients are still on the company's legacy mainframe systems. Currently, only new clients are serviced by the company's new cloud computing system. The long-term strategy is to migrate gradually from the legacy mainframe system to the new cloud computing system. The migration pace is languid. The primary challenge for programmers is understanding the business logic embedded in the mainframe code and then implementing the same logic in the Java programming language for the cloud computing system. It is challenging for company DEF to find versatile talents with expertise in technology and business functional knowledge.

Mr. Adma also mentioned the new IT trend of microservice architecture. An application is broken up into many small services with the microservice approach, which is more maintainable and testable. For example, on top of the Operating System there is a thin layer called a dock. Then on top of the dock, there is a layer of containers. Then on top of the containers, there are microservices. The primary purpose of microservices is scaleability. Mr. Adma told us about another hot IT trend, called Infrastructure as Code. An IT professional can run a script to set up infrastructure in the cloud in a few hours. In the past, it took a much longer time to set up infrastructure on-premises.

\section{Conclusion}

IS faculty has the responsibility of preparing future IS professionals with relevant skills. Therefore, IS faculty need to keep up with the new technology and trends in the IT industry. Towards this goal, we propose the approach of proactively seeking new knowledge in all social encounters. By exploiting the opportunities of these social interactions, IS faculty can obtain new knowledge and valuable insight for teaching. In this study, we demonstrated this approach with our practice. Furthermore, we reported 17 social encounters in a case study format. These 17 cases provide first-hand knowledge and rich information about emerging IT trends, industry and business insights, and career advice.

This research makes the following potential contributions. First, this study showcases how to broaden IS faculty's knowledge horizon to stay updated by actively exploiting social encounters. Second, the cases reported here can be adapted as teaching materials for classroom discussion in appropriate IS courses. Third, IS students will benefit from the industry insights, emerging technology trends, and career advice derived from the cases.

In the next stage of our study, we plan to conduct a detailed analysis of these 17 cases reported in this paper. Further analysis may reveal interesting patterns from the cases. Moreover, we are going to explore the implications and discuss them in the following paper. We acknowledge that our professional social network limits the cases described in this study. By extending our social network and knowledge sphere, we might come in touch with new knowledge. To extend this work, we will explore the possibility of integrating the case study with grounded theory to develop new insight (Halaweh, 2012). We expect to have new insights to report in the next stage of this research project. 


\section{Issues in Information Systems}

Volume 22, Issue 2, pp. 260-275, 2021

\section{References}

Darke, P., Shanks, G., \& Broadbent, M. (1998, October). Successfully completing case study research: Combining rigor, relevance, and pragmatism. Information Systems Journal, 8(4), 273-289.

Halaweh, M. (2012, March). Integration of grounded theory and case study: An exemplary application from e-commerce security perception research. (Y. J. Kim, Ed.) Journal of Information Technology Theory and Application, 13(1), 31-51.

Kuechler, W., McLeod, A., \& Simkin, M. G. (2009, Winter). Filling the pipeline for IS professionals: What can IS faculty do? Journal of Information Systems Education, 20(4), 407-418.

Lee, A. (1989, March). A scientific methodology for MIS case studies. MIS Quarterly, 13(1), 33-50.

Ngo-Ye, T. L., \& Baxter, J. (2015). Faculty informal self-learning and ways to engage students. Proceedings of the Southern Association for Information Systems Conference (SAIS 2015) (pp. 16). Hilton Head Island, SC, U.S.A.: Association for Information Systems. Retrieved May 28, 2016, from http://aisel.aisnet.org/sais2015/34

Ngo-Ye, T. L., McNeal, B., \& Gittens, D. (2017). Faculty social learning and enrichment of MIS courses. Issues in Information Systems, 18(4), 158-168. 